\title{
REASONS OF CONFLICTS IN TERTIARY CARE HOSPITAL: A CROSS SECTIONAL STUDY
}

\author{
Tahir Sardar, Muhammad Alamgir Khan*, Muhammad Naveed Akhtar*, Arshad Gul*
}

Armed Forces Post Graduate Medical Institute/National University of Medical Sciences (NUMS) Rawalpindi Pakistan, *Army Medical College/National University of Medical Sciences (NUMS) Rawalpindi Pakistan

\section{ABSTRACT}

Objective: To assess the reasons of conflicts in tertiary care hospital Rawalpindi.

Study Design: Cross sectional study.

Place and Duration of Study: Tertiary care hospital Rawalpindi, from Aug 2008 to Jul 2009.

Methodology: Hospital staff comprising of health administrators, clinicians, nurses and paramedics working in tertiary care hospital Rawalpindi were included in the study.

Results: These questions were asked to assess the general understanding of the respondents regarding the subject of conflicts to deduct their possible response in conflict situations. As per "Traditional" view conflict was considered as dysfunctional, destructive and irrational. The "Human relations view" describes conflict as natural, suggests tolerating it whereas the latest "inter-actionist view" defines conflict as a means for keeping us viable and creative, and suggests encouraging it. Average $44 \%$ of the respondents, mainly administrators and clinicians have fair idea regarding current concept of conflict.

Conclusion: Clinical and administrative staffs of hospitals are like parts of a train track. The irrational relationship between them will result in distortion and lower quality of services. Therefore, effective strategies to decrease staffs' experience of conflict need to be developed. This might create a healthier and more productive work environment which positively affects the care quality.

Keywords: Administrative staff, Clinical staff, Conflict causes, Conflict management, Tertiary care hospital.

This is an Open Access article distributed under the terms of the Creative Commons Attribution License (http://creativecommons.org/licenses/by/4.0), which permits unrestricted use, distribution, and reproduction in any medium, provided the original work is properly cited.

\section{INTRODUCTION}

A conflict is defined as a process when two interdependent parties perceive that they have incompatible goals and scarce resources and there is interference from each other on achieving these goals and gaining the resources ${ }^{1}$. In a convectional scenario, it is a dispute between no parties; that is characterized by overt expression of hostility or Intentional interference in the goal attainment of opposing party ${ }^{2}$.

In simple words, we can say that conflict is a process that begins when one party perceives that another party has negatively affected or is about to negatively affect something that the first party cares about Thomas (1946) has defined it more specifically and precisely as a process or state of mind which begins when one party perceives that another party has frustrated or is about to frustrate some concern of his. It is not necessarily good or bad but must be evaluated in terms of its individual and organizational function and dysfunction. Conflict often stems out from frustration, goals and roles ${ }^{3}$.

Conflict is more prevalent in the domain of hospitals due to certain inherent characteristics like heterogeneity of personnel, interdependence, specialization

Correspondence: Dr Tahir Sardar, Vice Principal, Army Medical College Rawalpindi Pakistan

Received: 16 Mar 2021; revised received: 10 Apr 2021; accepted: 12 Apr 2021 and various levels of authority. People working in a hospital environment belong to different cultures having different behavioral attitudes, I.Qs, education position and the comprehensive capabilities ${ }^{4}$. When they all work together, it is a fundamental sequence to have frictions among themselves which can cause conflicts and ultimately render great impacts on health delivery system. When people work together in a complex organization, there are numerous sources of conflict. Conflict increases with both the number of organizational levels and the number of specialties. It is greater as the degree of association increases and when some parties are dependent upon others ${ }^{4}$. Such conflicts of interest as competition for scarce resources, ambiguous jurisdictions, and the need for consensus all contribute to conflict. communication barriers impede understanding, and separations in time and space foster factionalism rather than mutual cooperation. Although standardized policies, rules, and procedures regulate behavior, make relationships more predictable, and decrease the number of arbitrary decisions, they impose added controls over the individual ${ }^{5}$. Men and women who value autonomy are likely to resist such control. Clearly, the sources of conflict are endless, and the numbers of conflicts increase as the number of unresolved differences accumulate. The magnitude of the conflict is tied to the numbers involved, their power relations, and the overall complexity of the 
organization. In teaching hospitals, where most health professions obtains the bulk of their learning experiences, there are usually a large number of diverse types of workers, power structures often arrayed in opposition to each other, and the complexity of the organization tends to increase all the time. Conflict situation can easily develop at micro and macro levels, as well as at every point in between ${ }^{6}$. It is no wonder that organizational conflict is common in such a dynamic atmosphere, where crisis management is often the rule rather than the exception, where the threat of malpractice suits is ever present, where the cost of the care may run counter to reimbursement policies, where the public believes that service is a right although governmental policies consider it a privilege, where science and technology are either stretching groups beyond their competency levels or rendering them obsolete and dispensable, and where rewards for contribution and commitment are often spread unevenly ${ }^{7}$. Conflict can occur even when the goals of two parties are compatible and the consequences will only be detrimental to everybody Involved. This kind of conflict has been labeled as pseudo-conflict. In general, this conflict generates pressure only but chronic conflict persists and has to be endured under certain conditions ${ }^{8}$.

In a flexible society, there are benefits of conflicts also because such behavior helps create and modify norms and can assist in continuation under changed conditions. In a diverse organizational environment, it creates tension which fosters institutional innovation. In a hospital setup, however, the welfare and the interest of the individual patient are best served by institutional stability and harmony. The friction generated by the conflict can be debilitating for the participant, rigidify the social system in which it occurs and leads to gross distortion of reality. A hospital administrator must therefore, be able to identify the underlying forces leading to various types of conflicts and exercise corrective intervention for timely resolution ${ }^{9}$. The objective of the study was to identify the major causes of conflicts in tertiary care hospital Rawalpindi and to recommend measures for prevention and resolution of conflicts. The population to benefit from the study includes the health professionals in general, hospital publics, and military medical administrators in particular.

\section{METHODOLOGY}

It was a cross sectional study conducted at tertiary care hospital at Rawalpindi from August 2008 to July 2009. Institutional Ethics Review Board Permission was taken ERC. Review of literature pertaining to the subject was carried out prior to the study. Guidance from senior consultants at different tertiary care hospital Rawalpindi was taken then structured questionnaire was constructed by their opinion. Data was collected through structured questionnaire and informal interviews of health administrators, clinicians, nurses and paramedics.

Hospital staff comprising ofhealth administrators, clinicians, nurses and paramedics working in tertiary care hospital Rawalpindi were included in the study. Hospital clients were excluded since the study of client-organization conflict was beyond the scope of the project. Study participants were recruited through consecutive convenient sampling. To get input from the stakeholders a structured questionnaire among the selected sample was circulated in the hospital Rawalpindi. The questionnaires were delivered and retrieved in person. For easy understanding, the nurses! Paramedics/Nursing assistants were briefed about various questions. Data was analyzed using SPSS-16. Descriptive statistics of the study questions were obtained.

\section{RESULTS}

Total sample population comprised of 90 participants. Out of which there were 15 administrators, 25 physicians, 25 Nurses and 25 nursing assistants. Response to the questionnaire was shown in the table-I.

Table-I: Response to the questionnaire.

\begin{tabular}{l|c|c}
\hline Category & Response & Percentage \\
\hline Administrators & 10 & 66.6 \\
\hline Physicians & 19 & 76 \\
\hline Nurses & 15 & 60 \\
\hline Nursing Assistants & 19 & 76 \\
\hline
\end{tabular}

In response to question: 'what feeling do you associate with the word conflicts?' $70 \%$ of administrators, $47 \%$ of physicians, $33 \%$ of Nurses and $32 \%$ nursing assistants agreed to answer " $\mathrm{c}$ " that is "it leads to innovation, encourage it'. For question, what will be your possible reaction to conflict if it gets to escalate? $42 \%$ of administrators, $40 \%$ of physicians, $37 \%$ of Nurses and $100 \%$ nursing assistants opted for answer " $\mathrm{C}$ " that is 'Try to Understand the issue' as shown in the table-II.

In response to question; 'in general are you satisfied with your jobs?' $80 \%$ of administrators, $89 \%$ of physicians, $100 \%$ of Nurses and $95 \%$ ) nursing assistants are satisfied with their job. In response to question: 'Are you subjected to prejudice / bias?' $80 \%$ of administrators, $89 \%$ of physicians, $100 \%$ of Nurses and 95\%) nursing assistants replied that they were subjec- 
ted to prejudice. In response to question: 'Do you have adequate facilities/opportunities for professional advancement in service e.g. post graduate training within or outside the country?' $30 \%$ of administrators, $47 \%$ of physicians, $73 \%$ of Nurses and 5\% nursing assistants agreed that they have opportunities for professional's advancement. In response to the Question: 'Is physical work load creating emotional stress for you?' $70 \%$ of administrators, $79 \%$ of physicians, $80 \%$ of Nurses and $21 \%$ nursing assistants agreed that heavy workload was creating emotional stress. In response to Question; Do you receive conflicting orders from your superiors ject of conflicts to deduct their possible response in conflict situations. As per "Traditional "view conflict was considered as dysfunctional, destructive and irrational. The "Human relations view" describes conflict as natural, suggests tolerating it whereas the latest "inter-actionist view" defines conflict as a means for keeping us viable and creative, and suggests encouraging it. Average $44 \%$ of the respondents, mainly administrators and clinicians have fair idea regarding current concept of conflict.

It is entirely appropriate to say that there has been

Table-II: Reasons of conflicts.

\begin{tabular}{|c|c|c|c|c|}
\hline Responses & Administrators & Physicians & Nurses & Paramedics \\
\hline \multicolumn{5}{|c|}{ Question No 1: What feeling do you associate with the word conflicts? } \\
\hline It is destructive & 2 & 3 & 5 & 8 \\
\hline It is natural, tolerate it & 1 & 7 & 5 & 5 \\
\hline It leads to innovation, encourage it & 7 & 9 & 5 & 6 \\
\hline \multicolumn{5}{|c|}{ Question No 2: What will be your possible reaction to conflict if it gets to escalate? } \\
\hline Put all energy in it & 1 & 5 & 4 & 7 \\
\hline Trying to be neutral & 1 & 6 & 5 & 5 \\
\hline Try to Understand the issue & 8 & 8 & 6 & 7 \\
\hline \multicolumn{5}{|c|}{ Questions No 3: In general are you satisfied with your jobs? } \\
\hline Yes & 8 & 17 & 15 & 18 \\
\hline No & 2 & 2 & - & 1 \\
\hline \multicolumn{5}{|c|}{ Question No 4: Are you subjected to prejudice / bias? } \\
\hline Yes & 5 & 12 & 10 & 15 \\
\hline No & 2 & 2 & 5 & 4 \\
\hline
\end{tabular}

Question No 5: Do you have adequate facilities / opportunities for professional advancement in service e.g. post graduate training within or outside the country?

\begin{tabular}{|c|c|c|c|c|}
\hline $\begin{array}{l}\text { Yes } \\
\text { No }\end{array}$ & $\begin{array}{l}3 \\
7\end{array}$ & $\begin{array}{c}9 \\
10\end{array}$ & $\begin{array}{c}11 \\
4\end{array}$ & $\begin{array}{c}1 \\
18\end{array}$ \\
\hline \multicolumn{5}{|c|}{ Question No 6: Is physical work load creating emotional stress for you? } \\
\hline $\begin{array}{l}\text { Yes } \\
\text { No }\end{array}$ & $\begin{array}{l}7 \\
3 \\
\end{array}$ & $\begin{array}{c}15 \\
4 \\
\end{array}$ & $\begin{array}{c}12 \\
3\end{array}$ & $\begin{array}{c}4 \\
15 \\
\end{array}$ \\
\hline \multicolumn{5}{|c|}{ Question No 7: Do you receive conflicting orders from your superiors making it impossible to comply? } \\
\hline $\begin{array}{l}\text { Yes } \\
\text { No }\end{array}$ & $\begin{array}{l}3 \\
7 \\
\end{array}$ & $\begin{array}{c}3 \\
16\end{array}$ & $\begin{array}{l}7 \\
8 \\
\end{array}$ & $\begin{array}{c}15 \\
4 \\
\end{array}$ \\
\hline \multicolumn{5}{|c|}{ Question No 8: Is there any ambiguity about the roles and responsibility assigned to you in this hospital? } \\
\hline $\begin{array}{l}\text { Yes } \\
\text { No }\end{array}$ & $\begin{array}{l}2 \\
8 \\
\end{array}$ & $\begin{array}{c}4 \\
15 \\
\end{array}$ & $\begin{array}{l}9 \\
6 \\
\end{array}$ & $\begin{array}{c}2 \\
17 \\
\end{array}$ \\
\hline
\end{tabular}

making it impossible to comply?' $30 \%$ of administrators, $16 \%$ of physicians, $47 \%$ of Nurses and $78 \%$ nursing assistants replied that they received conflicting orders. In response to Question: 'Is there any ambiguity about the roles and responsibility assigned to you in this hospital?' $20 \%$ of administrators, $21 \%$ of physicians, $60 \%$ of Nurses and $11 \%$ nursing assistants replied that there was role ambiguity.

\section{DISCUSSION}

These questions were asked to assess the general understanding of the respondents regarding the sub- conflict over the rule of conflicts in groups and organizations. One school of thought has argued that conflict must be avoided, that it indicates a malfunction within the group ${ }^{10}$. We call this the traditional view. Another school of thought, the human relations view, argues that conflict is a natural and inevitable outcome in any group. It need not be evil, but rather it has the potential to be a positive force in determining group performance. The third, and most recent, perspective proposes not only that conflict can be a positive force in a group, but explicitly argues that some conflict is abso- 
lutely necessary for a group to perform effectively. We label this third school the inter actionist view ${ }^{11}$.

The early approach to conflict assumed that conflict was bad. Conflict was viewed negatively, it was used synonymously with terms such as violence, destruction, and irrationality in order to reinforce its negative connection ${ }^{12}$. Conflict, then, was to be avoided. The traditional view was consistent with the attitudes that prevailed about group behavior in the 1930s and 1940s. From findings provided by studies such as those done at Hawthorne, it was argued that conflict was a dysfunctional outcome resulting from poor communication, a lack of openness and trust between people, and the failure of managers to be responsive to the needs and aspirations of their employees ${ }^{13}$.

The view that all conflict is bad certainly offers a single approach to looking at the behavior of people who create conflict. Since all conflict is to be avoided, we need merely direct our attention to the causes of conflict and correct these malfunctions in order to improve group and organizational performance. Although studies now provide strong evidence to dispute that this approach to conflict reduction results in high group performance, most of us still evaluate conflict situations on the basis of this outmoded standard ${ }^{14-16}$.

The human relations position argued that conflict was a natural occurrence in all groups and organizations. Since conflict was inevitable, the human relations school advocated acceptance of conflict. They rationalized its existence. It cannot be eliminated, and there are even times when conflict may benefit a group's performance. The human relations view dominated conflict theory from the late 1940s through the mid - 1970s ${ }^{10,16}$.

The current view toward conflict is the inter actionist perspective. Whereas the human relations approach accepted conflict, the inter actionist approach encourages conflict because a harmonious, peaceful, tranquil, and cooperative group is likely to become static, apathetic, and nonresponsive to needs for change and innovation. The major contribution of the inter actionist approach, therefore is encouraging group leaders to maintain an ongoing minimal level of conflictenough to keep the group alive, self - critical, and creative ${ }^{2,8}$.

Given the inter actionist view; it becomes evident that to say that conflict is all good or all bad is in appropriate and naive. Whether a conflict is good or bad depends on the type of conflict. Specifically, it's neces- sary to differentiate between functional and dysfunctional conflicts ${ }^{17}$.

The inter actionist view does not propose that all conflicts are good. Rather, some conflicts support the goals of the group and improve its performance; these are functional, constructive forms of conflict. There are also conflicts that hinder group performance; these are dysfunctional or destructive forms ${ }^{18}$.

What differentiates functional from dysfunctional conflict? The evidence indicates that you need to look at the type of conflict. Specifically, there are three types; task, relationship and process.

Relationship conflict focuses on interpersonal relationships. Process conflict relates to how the work gets done. Studies demonstrate that relationship conflicts are usually dysfunctional. Why? It appears that the friction and interpersonal hostilities inherent in relationship conflicts increase personality clashes and decrease mutual understanding, thereby hindering the completion of organizational tasks. On the other hand, low levels of process conflict and low-to- moderate levels of task conflict are functional. For process conflict to be productive, it must be kept low. Intense arguments about who should do what become dysfunctional when they create uncertainty about task roles, increase the time to complete tasks, and lead to members working at cross-purposes. A low-to-moderate level of task conflict consistently demonstrates a positive effect on group performance because it stimulates discussion of ideas that help groups perform better ${ }^{19}$.

Conflict can be good, bad or ugly and it can be managed in good, bad and ugly ways. With the public sector managers and supervisors, the Issue that generates the most emotion, and frustrated comments, is conflict within the organization. We generally do not look at conflict as opportunity - we tend to think about conflict as unpleasant, counter - productive and time consuming. Conflict that occurs in organizations need not be destructive, provided the energy associated with conflict is harnessed and directed towards problem-solving and organizational improvement. However, managing conflict effectively requires that all parties understand the nature of conflict in the workplace.

\section{CONCLUSION}

Clinical and administrative staff of hospitals is like parts of a train track. The irrational relationship between them will result in distortion and lower quality of services. Therefore, effective strategies to decrease staffs' experience of conflict need to be developed. 
This might create a healthier and more productive work environment which positively affects the care quality.

\section{CONFLICT OF INTEREST}

This study has no conflict of interest to be declared by any author.

\section{REFERENCES}

1. Guidroz AM, Wang M, Perez LM. Developing a model of sourcespecific interpersonal conflict in health care. Stress Health 2012; 28: 69-79.

2. Hendel T, Fish M, Berger O. Nurse/physician conflict management mode choices: Implications for improved collaborative practice. Nurs Adm Q 2007; 31: 244-53.

3. Akel DT, Elazeem HA. Nurses and physicians point of view regarding causes of conflict between them and resolution strategies used. Clin Nurs Stud 2015; 3(1): 112.

4. Barki H, Hartwick J. Conceptualizing the construct of interpersonal conflict. Int J Conflict Manage 2004; 15: 216-44.

5. Brinkert R. A literature review of conflict communication causes, costs, benefits and interventions in nursing. J Nurs Manag 2010; 18: $145-56$.

6. Elfering A, Gerhardt C, Grebner S, Müller U. Exploring supervisor-related job resources as mediators between supervisor conflict and job attitudes in hospital employees. Saf Health Work 2017; 8: 19-28.

7. Çınar F, Kaban A. Conflict management and visionary leadership: An application in hospital organizations. Procedia Soc Behav Sci 2012; 58: 197-206.

8. Nasiripour AA, Riahi L, Afzal E. The relationship between communication system and organizational conflict at hazraterassoul hospital Tehran. Sci J Manage Syst 2009; 20: 55-64.

9. Radfar F, Hozoori M, Tavafian SS. Comparison of the attitudes of hospital staff and managers towards managers' practice as regards conflict management in hospitals affiliated to Tehran
University of Medical sciences, 2008-2009. J Sch Public Health Inst Public Health Res 2011; 9: 59-66.

10. Hotepo O, Asokere A, Abdul-Azeez I, Ajemunigbohun S. Empirical study of the effect of conflict on organizational performance in Nigeria. J Bus Econ 2010; 20: 15-21.

11. Olajide T, Asuzu C, Obembe A. Doctor-nurse conflict in Nigeria hospitals: Causes and modes of expression. Br J Med Med Res 2015; 9(10): 1-12.

12. Sportsman S, Hamilton P. Conflict management styles in the health professions. J Prof Nurs 2007; 23(3): 157-66.

13. NekueiMoghaddam M, Taghavi Rad A, Hakimipour S, Shafiei M, Goudarzi G. Evaluation of relation between styles of conflict management and creativity of staff in teaching hospitals of Kerman city in 2008. J Hosp 2011; 9(1): 29-38.

14. Taghipour A, Dejban R, Khadem DZ, Naami A. Investigating relationship between communication skills and conflict resolution styles of managers with employee empowerment. Soc Psychol Res 2011; 1: 17-43.

15. Jerng JS, Huang SF, Liang HW, Chen LC, Lin CK, Huang HF, et al. Workplace interpersonal conflicts among the healthcare workers: Retrospective exploration from the institutional incident reporting system of a university-affiliated medical center. PLoS One 2017; 12: e0171696.

16. Baddar F, Salem OA, Villagracia HN. Conflict resolution strategies of nurses in a selected government tertiary hospital in the Kingdom of Saudi Arabia. J Nurs Educ Pract 2016; 6(5): 91.

17. Mosadeghrad AM, Arab M, Mojbafan A. Study of conflict management styles in Tehran University affiliated hospitals. J Health Based Res 2016; 2(1): 1-13.

18. Nasiripour A, Raeissi P, Nagaf Bagy R, Adabi A. The survey of structural factors in general hospitals of Yazd-Iran based on mechanic and organic approach 2012. Tolooebehdasht 2013; 12(3): 194-204.

19. Chen SY, Wu WC, Chang CS, Lin CT, Kung JY, Weng HC, et al Organizational justice, trust, and identification and their effects on organizational commitment in hospital nursing staff. BMC Health Serv Res 2015; 15(1): 363. 